Please do not remove this page

RMIT

UNIVERSITY

\title{
Reducing spurious radiation in edge-fed patch antennas
}

Rowe, Wayne; Waterhouse, Rod

https://researchrepository.rmit.edu.au/esploro/outputs/9921857923301341/filesAndLinks?institution=61RMIT_INST\&index=null

Rowe, W., \& Waterhouse, R. (2004). Reducing spurious radiation in edge-fed patch antennas. Proceedings of the IEEE International Antennas and Propagation Symposium \& URSI North American Radio Science Meeting, 3401-3404. https://doi.org/10.1109/APS.2004.1332110

Published Version: https://doi.org/10.1109/APS.2004.1332110

Repository homepage: https://researchrepository.rmit.edu.au

(c) 2004 IEEE. Personal use of this material is permitted. However, permission to reprint/republish this material for advertising or promotional purposes or for creating new collective works for resale or redistribution to servers or lists, or to reuse any copyrighted component of this work in other works must be obtained from the IEEE.

Downloaded On 2023/04/26 21:36:25 +1000 


\title{
Reducing Spurious Radiation in Edge-fed Patch Antennas
}

\author{
W. S. T. Rowe ${ }^{1}$ and R. B. Waterhouse ${ }^{2 *}$ \\ 'Australian Photonics Cooperative Research Centre \\ School of Electrical and Computer Engineering \\ RMIT University \\ Melbourne. Australia \\ Email: wanne.rowe@rmit.edu.an \\ ${ }^{2}$ Pharad LLC \\ Columbia, Maryland \\ Email: ruaterhouse@pharad.com
}

\section{Introduction}

There are several advantages of edge-feeding a microstrip patch over other direct contact and non-contact feeding techniques. One of the key features of this power distribution scheme is its ease of fabrication, as the feed network and radiating patches can be etched on the one board. It is for this reason that many large planar arrays have been developed using edge-fed patches. Edge-fed microstrip patches do however have relatively narrow impedance bandwidths, of the order of a couple of percent of the resonant frequency. A well documented means of enhancing the bandwidth of an edge-fed patch is to use thicker substrates. Unfortunately this relatively straightforward procedure does have its drawbacks. In particular, as the substrate thickness increases the width of the feed lines also increase, thereby generating more spurious radiation (or feed radiation). A consequence of this is the cross-polar radiation levels of the patch radiator increase, which can limit the performance of the antenna especially when it is configured in an array. For example, increasing the thickness by a factor of 2 can increase the bandwidth by a similar factor but also degrade the cross-polar radiation levels by the order of $10 \mathrm{~dB}$ or so [1].

In this paper, we investigate techniques to alleviate this problem with edge fed patches. In particular we explore two methods: using a thinner feed grounded substrate and then transitioning to a thicker substrate near the radiating patch; and then a variation of this, where under the thin substrate a metal block is incorporated. We found that the later method was required to prevent trapped energy beneath the thinner layer that contributed to higher levels of diffraction off the finite edges of the patch antenna. Experimental verification of the proposed techniques is presented and compared to a conventional edge-fed patch etched on a thick grounded substrate.

\section{Edge-fed Patch Configurations}

The conflicting substrate requirements for increasing the bandwidth and mitigating unwanted feed radiation from edge-fed patch antennas presents a 
design dilemma. As shown in Figure 1, a thick, low dielectric constant microwave laminate can be employed to achieve reasonable bandwidth $(-5 \%)$. However as the thickness of the substrate increases, the microstrip feed line must be broadened in order to maintain a $50 \Omega$ characteristic impedance. This gives rise to elevated feed radiation, causing pattern distortion.

To alleviate this predicament, we propose an edge fed patch with a dual thickness substrate. The majority of the microstrip feed line resides on thin dielectric layer with a ground plane directly underneath, requiring a thin track to achieve $50 \Omega$ characteristic impedance. A transition is then made to a thick substrate for a short section microstrip line and the patch antenna element.

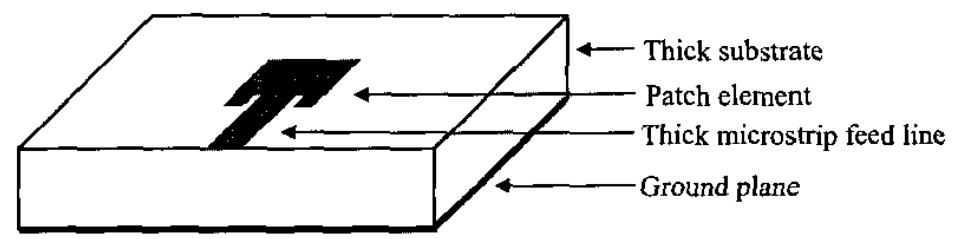

Figure 1. Conventional edge fed patch on thick substrate

Initially, the antenna was realized using two sheets of $1.575 \mathrm{~mm}$ thick Rogers RT/Duroid 5880 measuring approximately $100 \mathrm{~mm}^{2}$. The lower substrate consisted simply of a ground plane spanning the entire bottom surface. The upper substrate supported the patch element, and the two sections (thin and thick) of feed line on the top surface, and a small ground plane under the thin section of feed line on the reverse side. The two ground planes were joined together by the flange of an SMA connector mounted at the edge of the substrates. With the ground planes connected in this way, it was difficult to equalize their potential, particularly at the transition. We predicted that this would cause excessive field diffraction at the transition, and support parallel plate modes between the two ground planes.

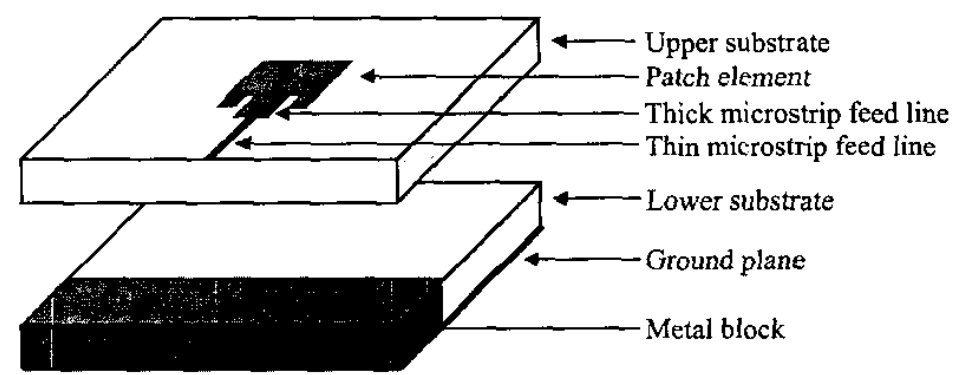

Figure 2. Dual thickness (with metal block) edge-fed patch antenna structure 
To improve the continuity of the ground plane at the transition, the second prototype had a metal block inserted below the small ground plane (see Figure 2). The lower substrate was trimmed to accommodate the metal block. The two ground planes and the SMA connector were affixed to the metal block with solder. This configuration also removes the parallel plate structure between the ground planes.

\section{Results and Discussion}

Figure 3 compares the measured return loss of the three edge-fed patch configurations. The conventional edge fed patch on a $3.175 \mathrm{~mm}$ thick Rogers RT/Duroid 5880 substrate and displays an impedance bandwidth (defined as having better than $10 \mathrm{~dB}$ return loss) of approximately $5.5 \%$. The initial dual thickness edge-fed patch antenna show a diminished bandwidth $(\sim 2 \%)$, and spurious resonances are observed due to parallel plate mode generation and field diffraction at the feed line transition. However, when the metal block was inserted below the small ground plane and the antenna parameters were optimizcd, a clean impedance response was observed with a bandwidth in excess of $4 \%$.

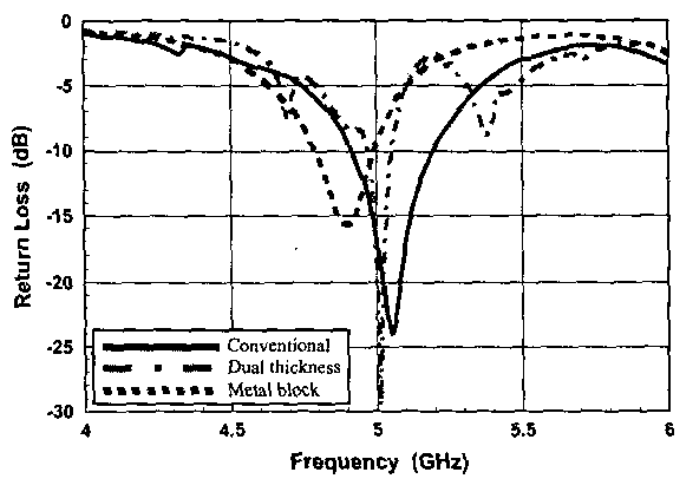

Figure 3. Measured return loss of the different configurations

The measurcd far field radiation patterns for the three antenna patterns are given in Figure 4. All three plots have been normalized to the same gain level. The conventional edge-fed patch antenna results in Figure 4(a) show severe pattern distortion in the E-plane co-polarized pattern caused by excessive feed radiation. For the initial dual thickness antenna in Figure $4(\mathrm{~b})$, the field diffraction at the transition produces acute deformation of the co-polarized patterns and highly elevated levels of cross-polarization. With the metal block under the small ground plane (Figure 4(c)), the E-plane distortion has been 
moderated in comparison to the conventional antenna. Lower crosspolarization is also observed for all angles in the E- and H-plane.

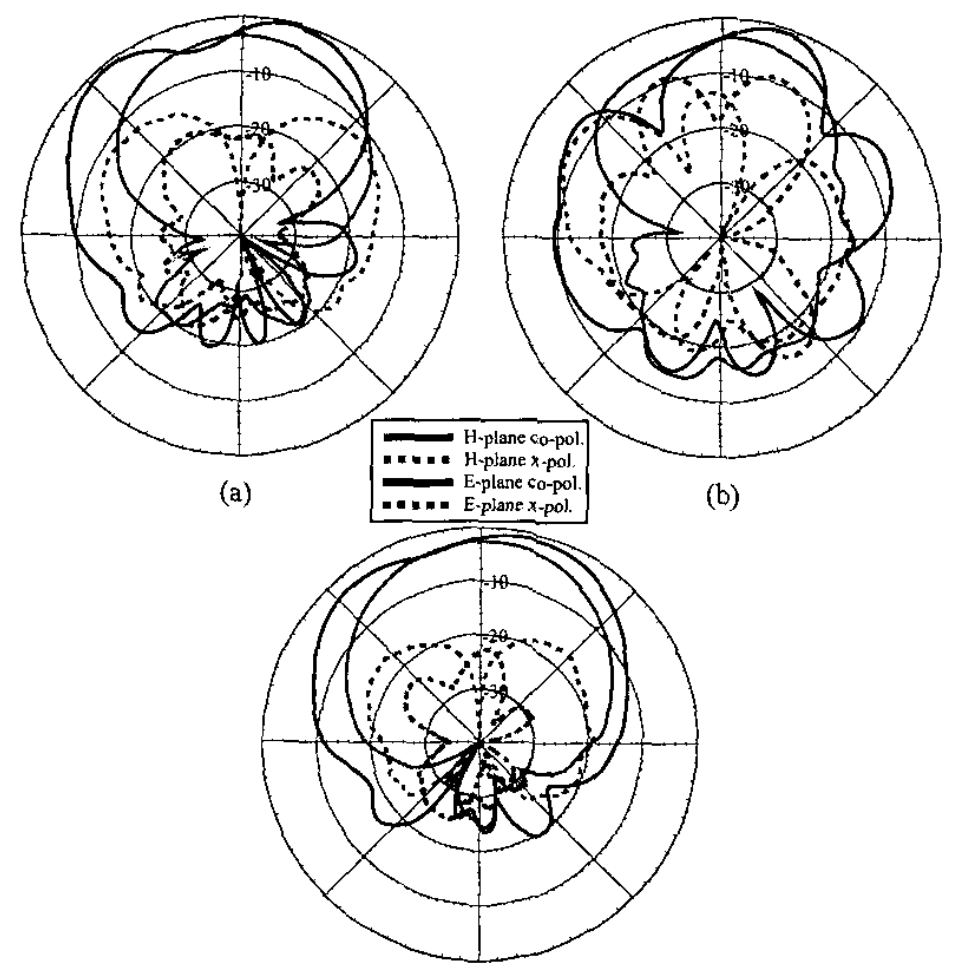

(c)

Figure 4. Measured radiation patterns of the different configurations

(a) Conventional ; (b) Dual thickness; (c) Metal block

\section{Conclusions}

A method to reduce the spurious feed radiation from edge-fed patch antennas by using a dual thickness substrate is presented. Measured results show decreased pattern distortion and diminished cross-polarized fields.

\section{References}

[1] R. B. Waterhouse, Microstrip Patch Antentras: A Designer's Guide, Kluwer, Boston, 2003. 